\title{
Prospecção no universo das águas: a experiência da construção de cenários no plano nacional de recursos hídricos no Brasil, 2005-2006
}

\author{
Elimar Pinheiro do Nascimento ${ }^{*}$ \\ Marco José Melo Neves** \\ Demetrios Christofidis
}

\section{Resumo}

O Plano Nacional de Recursos Hídricos foi aprovado em 2006 pelo Conselho Nacional de Recursos Hídricos. Pela primeira vez o Brasil tem um plano dessa natureza, com a peculiaridade de ter incluído um estudo prospectivo. Uma novidade, aparentemente, com dois precedentes no mundo. $\mathrm{O}$ presente artigo descreve a metodologia e o processo de criação dos cenários de recursos hídricos do plano, construídos por meio de um conjunto de oficinas regionais e nacionais que envolveram 235 participantes, e identifica as variáveis, os atores e as incertezas críticas do sistema de recursos hídricos no País. Desse conjunto de oficinas resultaram três cenários de recursos hídricos para o Brasil 2020, os quais foram parcialmente quantificados. Eles se transformaram na base do plano, a partir da definição de uma estratégia robusta, formada pela recorrência de

* Doutor em Sociologia, professor do Departamento de Sociologia e diretor do Centro de Desenvolvimento Sustentável da Universidade de Brasília-UnB (elimarcds@gmail.com).

** Engenheiro Agrícola, doutorando em Tecnologia Ambiental e Recursos Hídricos, técnico da Gerência de Planos de Recursos Hídricos da Secretaria de Recursos Hídricos e Ambiente Urbano do Ministério do Meio Ambiente - GAP/SRHU/MMA.

Engenheiro Civil, doutor em Desenvolvimento Sustentável, professor do Departamento de Engenharia Civil e do Centro de Desenvolvimento Sustentável da Universidade de Brasília - UnB.

Geosul, Florianópolis, v. 25, n. 49, p 27-62, jan./jun. 2010 
NASCIMENTO, E.P. do. et al. Prospecção no universo das águas: a ...

gargalos, potencialidades e conflitos na maioria dos cenários. Faltou, porém, uma quantificação mais refinada e completa, baseada em um modelo consistente, assim como uma focalização regional que permitisse identificar os impactos de cada um dos três cenários em cada uma das 12 regiões hidrográficas em que o País foi dividido.

Palavras-chave: Recursos hídricos; Planejamento; Plano nacional de recursos hídricos; Cenários de recursos hídricos; Metodologia de cenários; Participação social.

Prospecting the universe of waters: the experience of building scenarios for Brazil's national plan for water resources, 2005-2006

\section{Abstract}

Brazil's National Plan for Water Resources was approved in 2006 by the National Council for Water Resources. This was the first plan of its kind drafted in Brazil. Its most peculiar aspect is the inclusion of a prospective study, a component to be found in only two other similar national plans. This article describes the methodology adopted and the process of constructing the plan's water resources scenarios. These scenarios were built on the basis of a set of regional and national workshops, involving a total of 235 participants. They identified the variables, the actors and the critical uncertainties related to the country's water resources. Three scenarios emerged, partly quantified, valid for Brazil in 2020. They were used as the foundation of the plan, as a consequence of the adoption of a robust strategy that included the identification of recurrent bottlenecks, potentials and conflicts in the scenarios. However, it is argued that a more refined and complete quantification would have been required, based on a consistent model. Another shortcoming discussed in the text is the absence of a regional focus that would allow the identification of the impacts of each of the three scenarios in each of the 12 hydrographic regions into which the country was divided. 
NASCIMENTO, E.P. do. et al. Prospecção no universo das águas: a ...

Key words: Water resources; Planning, national plan for water resources; Water resources scenarios; Scenarios methodology; Social participation.

\section{Introdução}

Desde meados do séc. XX os estudos prospectivos têm se prestado a múltiplas finalidades, e as suas metodologias têm se sofisticado, ao mesmo tempo em que ganham mais operacionalidade. Neles, uso e estudo de cenários têm se destacado, com uma trajetória histórica recente, que começa em meados do século passado com Herman Khan (1967) e continua até os dias de hoje, sobretudo em grandes organizações e empresas multinacionais, como a Shell. Suas aplicações têm conhecido campos novos, além do das empresas e governos, adentrando organizações da sociedade civil (ONG e OSCIP), o mundo da política (partidos) e o da educação (universidades).

Em 2005, depois de quase uma década de trabalho, a Secretaria Nacional de Recursos Hídricos e Ambiente Urbano do Ministério do Meio Ambiente ${ }^{1}$ (SRHU/MMA) decidiu adotar uma metodologia prospectiva para apoiar o Plano Nacional de Recursos Hídricos.

A metodologia adotada, baseada nos trabalhos de Michel Godet (1993 e 2003) e da Macroplan (Porto, Nascimento e Buarque, 2001), foi aprovada naquele ano pela câmara técnica ${ }^{2}$ do Conselho Nacional de Recursos Hídricos (CT-PNRH/CNRH), criada com a precípua finalidade de elaborar e monitorar o Plano Nacional de Recursos Hídricos (PNRH).

\section{Os principais desafios do trabalho foram:}

a) como equilibrar, de um lado, a participação dos múltiplos atores interessados no acesso e uso dos recursos hídricos no País, particularmente os membros de comitês de bacia, usuários e governos estaduais, e, de outro lado, uma qualidade técnica, articulando, assim, legitimidade política e consistência técnica;

\footnotetext{
${ }^{1} \mathrm{Na}$ época, denominada Secretaria de Recursos Hídricos - SRH.

${ }^{2}$ Então dirigida por Francisco de Assis de Souza Filho.
} 
NASCIMENTO, E.P. do. et al. Prospecção no universo das águas: a ...

b) como articular os diversos e divergentes interesses desses atores em uma escrita lógica e consistente, que tivesse o mínimo de aceitação por eles;

c) como traduzir esse "arranjo de interesses" em hipóteses plausíveis e coerentes de futuros. Mas, sobretudo,

e) como criar uma base consistente, e inovadora, para a elaboração dos programas e projetos.

A participação na elaboração do PNRH foi concebida a partir da divisão do País em 12 regiões hidrográficas. Em cada uma delas foi implantada uma Comissão Executiva Regional (CER), congregando 200 atores das instâncias governamentais, do mercado e da sociedade civil. Esse trabalho se deu ao longo de um ano, sob a direção política da SRHU e com apoio técnico da Agência Nacional de Águas (ANA). Simultaneamente, foi realizado um amplo diagnóstico dos recursos hídricos no Brasil, por meio de equipes técnicas e discussões em oficinas e seminários nacionais e regionais de natureza temática. ${ }^{3}$

Com o intuito de definir os insumos para a construção de cenários foram realizadas 36 oficinas regionais ${ }^{4}$, que analisaram a situação especifica de cada região hidrográfica e um conjunto inicial de 53 variáveis definidas pela CT-PNRH, simultaneamente, integrantes e definidoras dos diversos sistemas de recursos hídricos (ver Anexo 1).

Esses insumos permitiram, por meio de duas oficinas nacionais, com a presença de 35 participantes de origens diversas, desde especialistas até representantes das instâncias societais e governamentais, construir três cenários, que foram parcialmente quantificados e permitiram estruturar uma base para a elaboração das diretrizes e programas do PNRH.

${ }^{3} \mathrm{O}$ diagnóstico foi baseado em um conjunto de documentos técnicos e aportes de reuniões, constantes do item seguinte $-A$ estruturação do processo de participação no PNRH.

${ }^{4}$ Três oficinas em cada uma das 12 regiões hidrográficas. 
NASCIMENTO, E.P. do. et al. Prospecção no universo das águas: a ...

A metodologia adotada utilizou os recursos ${ }^{5}$ da escola racional de cenários (MINTZBERG, 1990), sem esquecer as sugestões de Heidjen (2004) sobre a arte da conversação estratégica. Sua principal aquisição, porém, residiu na enorme capacidade de envolver atores das mais distintas origens e articular seus interesses em um relato coerente, consistente e plausível, possibilitando uma base razoável para a formulação dos programas e projetos que constituem o "núcleo duro" do PNRH.

\section{A estrutura do PNRH}

O Plano Nacional de Recursos Hídricos (PNRH), aprovado em janeiro de 2006, tem como objetivo geral estabelecer um pacto nacional para a definição de diretrizes e políticas públicas voltadas para a melhoria da oferta de água, em quantidade e qualidade, para as diversas atividades humanas, sem esquecer o papel essencial que os recursos hídricos desempenham na existência (e reprodução) dos ecossistemas onde estão inseridos. Supõe-se que o plano propicie o gerenciamento das demandas, considerando a água um elemento estruturante para a implantação de políticas setoriais voltadas ao desenvolvimento sustentável e à inclusão social.

O PNRH está estruturado em quatro volumes, elaborados de forma seqüencial e tendo como base de informações doze Cadernos Regionais ${ }^{6}$, cinco Cadernos Setoriais $^{7}$, além dos relatórios das oficinas e seminários realizados.

O primeiro volume - Panorama e estado dos recursos hídricos do Brasil - apresenta o diagnóstico dos recursos hídricos,

${ }^{5}$ Entre eles a análise morfológica, como ver-se-á em seguida.

6 Cadernos Regionais da Amazônia, Tocantins-Araguaia, Atlântico Nordeste Ocidental, Parnaíba, Atlântico Nordeste Oriental, São Francisco, Atlântico Leste, Atlântico Sudeste, Atlântico Sul, Paraguai, Paraná e Uruguai, publicados pelo Ministério de Meio Ambiente.

7 Cadernos dos setores de Saneamento, Agropecuário, Indústria e Turismo, Transporte Aquaviário e de Geração Hidrelétrica, publicados pelo Ministério de Meio Ambiente. 
NASCIMENTO, E.P. do. et al. Prospecção no universo das águas: a ...

abordando aspectos da evolução da legislação e do sistema de gerenciamento de recursos hídricos, e questões técnicas como disponibilidade hídrica, demandas pelo uso da água e sua qualidade (Plano Nacional de Recursos Hídricos, 2006a).

Águas para o futuro - cenários para 2020 é o segundo volume. Apresenta o processo de desenvolvimento dos estudos prospectivos e os três cenários resultantes: Água para Todos, Água para Alguns, Água para Poucos. Conclui com a proposição de uma estratégia, denominada de robusta, para a elaboração do plano (Plano Nacional de Recursos Hídricos, 2006b).

O terceiro volume - Diretrizes - apresenta o processo de estruturação e as 64 macrodiretrizes do PNRH, oferecendo elementos para a estruturação dos seus programas (Plano Nacional de Recursos Hídricos, 2006c).

O quarto volume - Programas nacionais e metas - estrutura as proposições do Plano em quatro componentes, treze programas e trinta subprogramas, abordando o desenvolvimento da gestão integrada dos recursos hídricos, a articulação inter-setorial, interinstitucional e intra-institucional, programas regionais de recursos hídricos e o gerenciamento do processo de implantação do plano (Plano Nacional de Recursos Hídricos, 2006d). Nesse volume são apresentadas as seis metas emergenciais que devem ser alcançadas até o final de $2008 .^{8}$

${ }^{8}$ Meta 1 - Elaborar e aprovar no âmbito do CNRH documento denominado Estratégia de Implementação do PNRH. Meta 2 - Desenvolver, propor e aprovar, no âmbito do CNRH, um Sistema de Gerenciamento Orientado para os Resultados do PNRH - SIGEOR. Meta 3 - Detalhar e implementar o Sistema de Implantação, Monitoramento e Avaliação do PNRH e o Subsistema de Informações de Monitoramento e Avaliação do PNRH. Meta 4 - Detalhar o Programa III - Desenvolvimento e Implementação de Instrumentos de Gestão de Recursos Hídricos e 5 dos seus 9 Subprogramas. Meta 5 - Detalhar os Programas e Subprogramas para os componentes: Gestão Nacional e Gerenciamento Integrado. Meta 6 - Detalhar os Programas e Subprogramas do Componente de Programas Regionais de Recursos Hídricos. 
NASCIMENTO, E.P. do. et al. Prospecção no universo das águas: a ...

\section{Os cenários de recursos hídricos no âmbito mundial}

O uso de cenários prováveis e exploratórios no planejamento de recursos hídricos ainda é uma novidade, especialmente em se tratando de sua aplicação no âmbito de bacias hidrográficas. A sua aplicação tem sido mais comum em estudos de âmbitos geográficos e setoriais mais abrangentes. ${ }^{9}$

No plano internacional, há duas experiências de estudos prospectivos na área de recursos hídricos que merecem destaque. A primeira foi o desenvolvimento de uma Visão Mundial da Água (World Water Council, 2000) pelo Conselho Mundial da Água, que envolveu mais de 15 mil pessoas em todo o mundo, objetivando explicitar aspirações e estratégias de desenvolvimento de ações práticas para o uso sustentável e o manejo dos recursos hídricos. Foram elaborados cenários prospectivos qualitativos, com a quantificação de algumas variáveis. A Visão Mundial da Água inclui contribuições de profissionais e atores que desenvolveram visões regionais integradas em mais de quinze regiões do mundo. Os resultados foram apresentados pela Comissão Mundial de Água para o Século 21, no segundo Fórum Mundial da Água, realizado em 2000, na Holanda.

A segunda experiência, de âmbito global, que adotou a cenarização prospectiva, enfocando a temática ambiental e de recursos hídricos, foi realizada em 2003 pelo Programa das Nações Unidas para o Meio Ambiente (PNUMA). A iniciativa fez parte da série Global Environment Outlook (PNUMA, 2004) em sua terceira edição. Foram desenvolvidos cenários qualitativos (narrativos) e realizadas quantificações, com a utilização de alguns modelos. $\mathrm{O}$ exercício contou com a participação de aproximadamente mil pessoas e quarenta instituições em todo o mundo.

No Brasil nunca ocorreram semelhantes experiências antes do PNRH, provavelmente pelo caráter conservador das instituições

${ }^{9}$ Ver, por exemplo, os estudos de cenários da Eletronorte sobre a Amazônia, ou da Macroplan, no setor elétrico. 
NASCIMENTO, E.P. do. et al. Prospecção no universo das águas: a ...

estatais e pelo pouco prestígio que ainda possuem as técnicas de construção de cenários no País.

\section{O processo de elaboração do PNRH}

No âmbito nacional o uso de cenários exploratórios é muito recente. Não tem mais que trinta anos. No caso de recursos hídricos, é inédito.

O processo de construção do Plano Nacional de Recursos Hídricos (PNRH) não foi trivial. Ao contrário, foi longo e trabalhoso. ${ }^{10}$ Três momentos distintos podem ser visualizados no seu desenvolvimento.

O primeiro ocorre em 1997, com a instituição da Política Nacional de Recursos Hídricos, na qual é prevista a elaboração do PNRH como um dos instrumentos para a boa gestão dos recursos hídricos.

O segundo momento, a partir de 1998, teve como fatos importantes a entrega e discussão de um documento de subsídio ao Plano Nacional de Recursos Hídricos, elaborado pela Fundação Getúlio Vargas (FGV) ${ }^{11}$, a criação da Câmara Técnica do PNRH (CT-PNRH) em 1999, no âmbito do Conselho Nacional de Recursos Hídricos (CNRH), e a criação da Agência Nacional de Águas (ANA), em 2000.

A criação da ANA teve como conseqüência imediata mais importante, como só acontece nessas ocasiões, a indefinição quanto à coordenação política do processo do PNRH.

No terceiro momento, que transcorreu entre 2003 e 2006, o processo metodológico do PNRH foi estruturado tendo a SRH como

${ }^{10}$ As iniciativas anteriores de elaboração de um PNRH foram duas: em 1984, com o Departamento Nacional de Água e Energia Elétrica DNAEE e, em 1996, resultante de um acordo ${ }^{10}$ celebrado entre o Ministério do Meio Ambiente e a Fundação Getúlio Vargas, que assumiu a responsabilidade técnica pela sua execução.

11 MMA/ Secretaria de Recursos Hídricos. Plano Nacional de Recursos Hídricos. FGV, Brasília, 1998. $10 \mathrm{v}$. 
NASCIMENTO, E.P. do. et al. Prospecção no universo das águas: a ...

responsável por sua coordenação política, segundo o Decreto 4.755 de 20 de junho de $2004^{12}$. À ANA coube o apoio técnico à formulação do plano e a coordenação da sua implantação. Essa decisão criou as condições favoráveis para a elaboração e posterior aprovação pelo $\mathrm{CNRH}$, pois no primeiro ano desse período já havia uma câmara técnica funcionando, um grupo executivo atuando, as diretrizes gerais estabelecidas e um documento inicial consolidado. ${ }^{13}$

Considerando as disposições legais e as necessidades do Sistema Nacional de Gerenciamento de Recursos Hídricos (SINGREH), o grupo técnico de coordenação e elaboração do PNRH (GTCE) propôs à Câmara Técnica uma nova Divisão Hidrográfica Nacional ${ }^{14}$, conforme a Figura 1. O Brasil foi dividido em 12 regiões hidrográficas: Amazônia, Atlântico Nordeste Ocidental, Parnaíba, Atlântico Nordeste Oriental, TocantinsAraguaia, São Francisco, Atlântico Leste, Atlântico Sudeste, Paraná, Paraguai, Uruguai e Atlântico Sul.

\section{Participação social e estudos técnicos na elaboração do PNRH}

A estruturação do processo de elaboração do plano, definida metodologicamente por uma gerência estruturada no âmbito da SRHU/MMA, alicerçou-se na participação social e no estabelecimento de uma base técnica consistente para subsidiar as discussões e as deliberações dos atores convidados, destacando-se: ratificação da dominialidade pública das águas; usos múltiplos das

${ }^{12}$ E subseqüentes $5.776 / 2005$ e $6.101 / 2007$.

${ }^{13}$ Outras conquistas importantes para o processo do plano: a sua inclusão no Plano Plurianual do Governo Federal (PPA 2004/2007), a sua priorização no âmbito da SRH/MMA e a estruturação de uma equipe técnica, a partir de fevereiro de 2004, suprida a partir de concurso público do Ministério do Meio Ambiente realizado de acordo com o Edital 1/2003, de 28.8.2003.

${ }^{14} \mathrm{~A}$ nova divisão foi aprovada pelo $\mathrm{CNRH}$ e instituída pela Resolução CNRH $\mathrm{n}^{\mathrm{o}}$ 32, de 15.10.2003, com a finalidade de orientar e fundamentar o Plano Nacional de Recursos Hídricos. 
NASCIMENTO, E.P. do. et al. Prospecção no universo das águas: a ...

águas, com prioridade para o consumo humano; reconhecimento do seu valor econômico; adoção da bacia hidrográfica como unidade territorial para implantação da política, descentralização e participação social no processo de gestão e utilização integrada e sustentável da água.

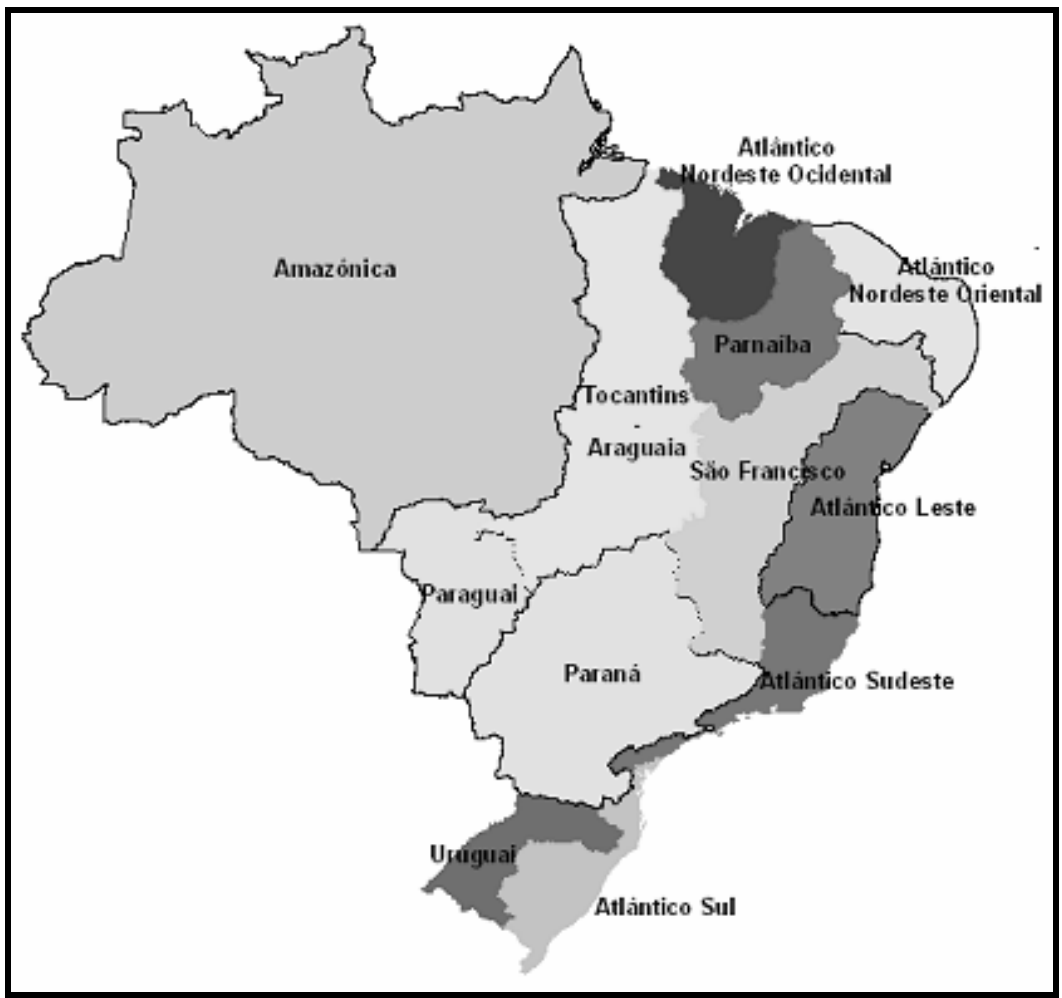

Figura 1: Divisão Hidrográfica Nacional, segundo a Resolução $\mathrm{CNRH} \mathrm{N}^{\circ} 32$, de 15.10.2003.

Fonte: PNRH, 2006.

A participação social foi concebida não apenas para a construção dos cenários, mas desde o início da construção do Plano, quando se começou a elaboração do diagnóstico. Para isso 
NASCIMENTO, E.P. do. et al. Prospecção no universo das águas: a ...

foram adotadas duas vertentes de trabalho interdependentes, uma nacional e outra regional.

$\mathrm{Na}$ vertente nacional se organizaram os temas e questões estratégicos voltados para efetivar a gestão integrada dos recursos hídricos. No tocante à vertente regional, foram focadas questões referentes à realidade regional dos recursos hídricos, buscando explicitar as incertezas críticas e prioridades de cada região onde foram criadas comissões executivas nacionais. ${ }^{15}$

O processo de planejamento participativo, em seu conjunto, envolveu aproximadamente 7.000 pessoas em todo o País nas reuniões regionais e nacionais. A construção dos cenários contou com a participação dos 200 membros das 12 comissões executivas regionais e dos 35 participantes das duas oficinas nacionais.

Para a construção dos cenários propriamente ditos, foram realizadas três reuniões em cada uma das 12 regiões hidrográficas, nos meses de junho e julho de 2005 , e duas oficinas nacionais, nos meses de setembro e outubro do mesmo ano.

A metodologia prospectiva permitiu envolver um grande número de participantes, orientar o debate público para a construção estratégica coletiva de um futuro almejado, contribuir para um interessante processo de aprendizagem organizacional no âmbito do Sistema Nacional de Gerenciamento de Recursos Hídricos. Isso tudo permitiu um melhor entendimento, tanto dos aspectos ambientais quanto dos aspectos sociais e institucionais relacionados aos recursos hídricos no País.

Os cenários foram apoiados por uma larga e consistente base técnica que veio a compor o diagnóstico do sistema de recursos

15 As Comissões Executivas Regionais tinham uma estrutura quadripartite, com representações do Governo Federal, sistemas estaduais de gerenciamento de recursos hídricos, sociedade civil e usuários da água. Na sua maioria as CER eram compostas por quatro representantes de cada um dos segmentos mencionados. 
NASCIMENTO, E.P. do. et al. Prospecção no universo das águas: a ...

hídricos no Brasil. ${ }^{16}$ Essa base foi composta pelo Documento Base de Referência - DBR (MMA, 2005), pelo conjunto de seis estudos nacionais realizados pela Agência Nacional de Águas (ANA, 2002a, $\mathrm{b}, \mathrm{c}, \mathrm{d}, \mathrm{e}, \mathrm{f}$ ), por doze cadernos regionais de recursos hídricos (MMA, 2006a, b, c, d, e, f, g, h, i, j, k, l) desenvolvidos em articulação com as Comissões Executivas Regionais (CER) e cinco cadernos setoriais de recursos hídricos (MMA, 2006m, n, o, p, q), que apresentam uma análise da dinâmica dos principais setores usuários de recursos hídricos e de suas relações mútuas. Ademais, a base técnica contou com relatórios de três oficinas temáticas, as oficinas setoriais, e do Seminário Nacional de Diretrizes e Programas, ocorridos entre os meses de março de 2004 e novembro de 2005.

\section{O que são cenários e para que servem?}

Cenários são aqui entendidos como hipóteses, coerentes e plausíveis, de futuro. Essa definição simples tem a qualidade, em primeiro lugar, de chamar atenção para o fato de que os cenários dizem respeito a hipóteses, portanto, são conjecturas e não teses ou teorias. São conjecturas que se autoproclamam como tais, e desta maneira afirmam, de forma peremptória, que não se trata de qualquer tentativa de adivinhar o futuro. Em segundo lugar, são hipóteses que têm a marca da coerência, articulando as suas diversas variáveis de forma lógica e sistêmica. Finalmente, baseiam-se na factibilidade, buscando sempre definir seu caráter de probabilidade.

As vantagens de se adotar uma metodologia de construção de cenários na elaboração de um plano, seja ele ou não de recursos hídricos, são múltiplas, tanto no processo de construção quanto no seu uso. Entre as vantagens que se referem à sua construção podem-se citar três, entre as mais importantes.

A primeira refere-se ao fato de que é possível abordar a realidade em tela de forma sistêmica, evitando-se as visões

${ }^{16}$ Ver os trabalhos da Agência Nacional de Águas - ANA 2002 a, 2002b, 2002c, 2002 d, 2202e, 2002f. 
NASCIMENTO, E.P. do. et al. Prospecção no universo das águas: a ...

estanques de suas variáveis. $\mathrm{O}$ objeto de uma cenarização é sempre concebido como um sistema, com história própria, variáveis e atores interligados e em retroalimentação. Dessa forma, estudos distintos podem ser articulados e relacionados em uma visão de conjunto sobre o objeto de cenarização, o que raramente acontece em diagnósticos.

A segunda vantagem reside na criação de um espaço de participação relativamente amplo. Conforme citado anteriormente, o processo direto de construção de cenários envolveu 235 participantes de todas as unidades da federação. Isso incluiu atores representativos das esferas estatais e dos seus poderes, como dos diversos segmentos da sociedade civil e do mercado, além de especialistas de distintas áreas do conhecimento concernente à compreensão do sistema de recursos hídricos. Evidentemente que esse aspecto comporta riscos, tais como o de querer fundar a construção dos cenários exclusivamente em atores que não têm a visão do conjunto dos problemas e suas tendências, ou que não sejam representativos da evolução do sistema. Para evitá-los é essencial casar a presença de atores com interesses claros e especialistas do sistema de recursos hídricos.

Finalmente, a terceira é que a metodologia cria um espaço de negociação entre os interesses divergentes ou diferentes dos múltiplos atores participantes, particularmente entre os usuários dos recursos hídricos, cujos interesses são, muitas vezes, opostos. Como o confronto se faz em um espaço de simulação e remete a um tempo longínquo, as condições são mais favoráveis para explicitação e negociação de interesses.

Também a posteriori as vantagens da adoção do ponto de vista prospectivo são inúmeras, bastando destacar duas.

A primeira prende-se ao fato de que os cenários permitem antecipar potencialidades, gargalos e conflitos que uma política pública responsável pode evitar ou pelo menos reduzir parte de seus efeitos nefastos, além de permitir que os atores se organizem para enfrentar, ou aproveitar, essas possíveis situações futuras. 
NASCIMENTO, E.P. do. et al. Prospecção no universo das águas: a ...

A segunda vantagem é que os cenários constituem um espaço favorável ao monitoramento da evolução dos conflitos e gargalos presentes no sistema de recursos hídricos, possibilitando uma gestão mais consistente e, sobretudo, previdente.

A apropriação dessas vantagens, que não é automática, depende em grande parte da metodologia adotada. Aparentemente, aquela adotada no PNHR permitiu o afloramento das vantagens próprias à fase de construção. Senão, vejamos.

\section{Metodologia da construção dos cenários}

Os cenários, na metodologia escolhida, nascem de um processo que percorre sete etapas:

1. Definição do escopo do objeto de cenarização

$\mathrm{Na}$ estruturação do escopo do objeto de cenarização foi definido o horizonte de 2020, correspondendo, portanto, a quinze anos. O ideal teria sido vinte anos. No entanto, foi necessário definir um período menor, de maneira a ficar compatível com o estudo que vinha sendo utilizado pelo Ministério do Planejamento, Orçamento e Gestão (MPOG) no processo de atualização do portfólio dos eixos nacionais de integração e desenvolvimento. $\mathrm{O}$ objeto da cenarização, por sua vez, foi definido como sendo o conjunto das variáveis e atores que conformam o Sistema Nacional de Recursos Hídricos. Por sua vez, a lógica do sistema residiu em assegurar: a) o uso múltiplo dos recursos hídricos pelos diversos usuários, com prioridade para o abastecimento humano; b) a qualidade das águas, em conformidade com os seus diversos usos; c) a quantidade necessária das águas, para responder às diversas demandas, segundo os objetivos nacionais ${ }^{17}$ e, finalmente, d) a sustentabilidade ambiental, com o objetivo de assegurar a reprodução dos diversos ecossistemas.

17 Os macroobjetivos nacionais, segundo a Constituição de 1988, são: erradicar a pobreza, reduzir a desigualdade e assegurar o bem-estar social para todos os membros do corpo da Nação. 
NASCIMENTO, E.P. do. et al. Prospecção no universo das águas: a ...

2. Análise estrutural

Para a definição das variáveis relevantes para o sistema de recursos hídricos o grupo técnico de coordenação e elaboração do PNRH (GTCE) propôs um conjunto inicial de 120 variáveis. Elas foram redefinidas e reagrupadas em um total de 53, após debates na câmara técnica, durante um período que se estendeu de abril a junho de 2004. Em seguida elas foram submetidas às oficinas regionais, para a realização da análise estrutural. ${ }^{18}$

Essa análise objetiva identificar e classificar as variáveis e o seu jogo de mútuas influências, na busca de identificar quais as incertezas críticas, ou seja, as variáveis de maior grau de incerteza e mais capacidade de influência sobre o sistema como um todo. A análise estrutural classifica as variáveis em quatro tipos:

a) motrizes - responsáveis principais pela evolução do sistema, por sua alta capacidade de influência;

b) de ligação - que intermedeiam o jogo de influência no âmbito do sistema;

c) de resultado - receptoras principais das influências do sistema, servindo de indicadoras de sua evolução, e;

d) autônomas - ou seja, com baixa relação com o sistema, tendo relativa independência em relação a outras variáveis.

A ferramenta utilizada na análise estrutural foi a matriz de análise de variáveis, duas a duas, denominada URCA (unidirecional, reversa, circular e ausente de interferências, de acordo com Marques, 2004).

O resultado foi a definição de um conjunto de 18 incertezas críticas para os recursos hídricos nas regiões hidrográficas, tomados como insumo para a etapa seguinte, a de investigação morfológica.

Finalmente, na oficina nacional de construção de cenários essas incertezas foram reduzidas a um conjunto de cinco macroincertezas, que somadas a outras duas referentes aos contextos internacional e nacional, cedidos gentilmente pela

${ }^{18}$ Vide Anexo 1. 
NASCIMENTO, E.P. do. et al. Prospecção no universo das águas: a ...

Macroplan $^{19}$, resultaram em sete incertezas críticas contempladas na investigação morfológica.

3. Investigação morfológica

A investigação morfológica consiste na combinação lógicoracional dos estados possíveis das incertezas críticas selecionadas, ou seja, as suas expressões concretas mais prováveis, tomando em consideração a natureza e a provável evolução de cada uma delas. Com isso são construídas as combinações mais prováveis segundo as percepções dos participantes, conforme pode ser visualizado no Quadro 1.

Da aplicação da investigação morfológica resultam arquétipos de cenários que são em seguida submetidos a testes de plausibilidade e consistência. No caso resultaram seis arquétipos ou sugestões de cenários.

Se os passos anteriores da metodologia se deram no âmbito da CT e das CER, a investigação morfológica foi objeto de trabalho da primeira oficina nacional de construção de cenários que reuniu especialistas e participantes representativos dos mais importantes usuários dos recursos hídricos, em número de 35, realizada entre 12 e 15 de setembro de 2005.

${ }^{19}$ A Macroplan - Planejamento, Estratégia e Gestão é uma das empresas mais conceituadas do País na elaboração de estratégias organizacionais para empresas e governos. Agradecemos a seu diretor-presidente Claudio Porto a cessão dos cenários macromundiais e nacionais produzidos pela empresa. Sobre a Macroplan ver o site www.macroplan.com.br. 
NASCIMENTO, E.P. do. et al. Prospecção no universo das águas: a ...

Quadro 1: Estados plausíveis das Incertezas Críticas na construção dos cenários do PNRH

\begin{tabular}{|l|c|c|c|c|}
\hline \multicolumn{1}{|c|}{ Incertezas } & \multicolumn{4}{|c|}{ Hipóteses } \\
\hline $\begin{array}{l}\text { 1. Cenários } \\
\text { mundiais }\end{array}$ & $\begin{array}{c}\text { Longo ciclo de } \\
\text { prosperidade }\end{array}$ & $\begin{array}{c}\text { Dinamismo } \\
\text { excludente }\end{array}$ & $\begin{array}{c}\text { Instabilidade e } \\
\text { fragmentação }\end{array}$ & \\
\hline $\begin{array}{l}\text { 2. Cenários } \\
\text { nacionais }\end{array}$ & $\begin{array}{c}\text { Desenvolvimento } \\
\text { integrado }\end{array}$ & $\begin{array}{c}\text { Modernização } \\
\text { com exclusão }\end{array}$ & $\begin{array}{c}\text { Crescimento } \\
\text { endógeno }\end{array}$ & $\begin{array}{c}\text { Estagnação e } \\
\text { pobreza }\end{array}$ \\
\hline $\begin{array}{l}\text { 3. Atividades } \\
\text { econômicas }\end{array}$ & $\begin{array}{c}\text { Crescimento e } \\
\text { fortes impactos }\end{array}$ & $\begin{array}{c}\text { Crescimento e } \\
\text { médios } \\
\text { impactos }\end{array}$ & $\begin{array}{c}\text { Médio } \\
\text { crescimento e e } \\
\text { fortes } \\
\text { impactos }\end{array}$ & $\begin{array}{c}\text { Médio } \\
\text { crescimento } \\
\text { e médios } \\
\text { impactos }\end{array}$ \\
\hline $\begin{array}{l}\text { 4. Usinas } \\
\text { hidroelétricas }\end{array}$ & Forte expansão & $\begin{array}{c}\text { Média } \\
\text { expansão }\end{array}$ & $\begin{array}{c}\text { Pouca } \\
\text { expansão }\end{array}$ & \\
\hline $\begin{array}{l}\text { 5. Saneamento } \\
\text { Participação } \\
\text { privada }-\end{array}$ & $\begin{array}{c}\text { Participação } \\
\text { privada e } \\
\text { expansão }\end{array}$ & $\begin{array}{c}\text { Estatal com } \\
\text { eficiência }\end{array}$ & $\begin{array}{c}\text { Estatal sem } \\
\text { eficiência }\end{array}$ \\
\hline $\begin{array}{l}\text { 6. Gestão } \\
\text { integrada }\end{array}$ & Liberal & Burocrática & Operativa & \\
\hline $\begin{array}{l}\text { 7. Investimentos } \\
\text { em proteção } \\
\text { de RH }\end{array}$ & $\begin{array}{c}\text { Grandes e } \\
\text { massivos }\end{array}$ & $\begin{array}{c}\text { Grandes e } \\
\text { seletivos }\end{array}$ & $\begin{array}{c}\text { Médios e } \\
\text { massivos }\end{array}$ & $\begin{array}{c}\text { Médios e } \\
\text { seletivos }\end{array}$ \\
\hline
\end{tabular}

Fonte: PNHH, 2006.

4. Teste de plausibilidade política dos cenários gerados

Esse teste, no caso realizado pela equipe técnica que conduziu a construção dos cenários ${ }^{20}$, consiste no cruzamento dos interesses dos atores em relação aos arquétipos de cenários anteriormente construídos. Ele permite que se identifiquem quais os cenários com maior ou menor promoção entre os atores mais relevantes. Estes, por sua vez, foram selecionados a partir da lista

${ }^{20}$ Além dos membros da SRH, participaram da equipe: Elimar Pinheiro do Nascimento, Suzy Theodoro, Antunes Cerqueira, Joana Ramos Ramalho e Vinicius de Carvalho. 
NASCIMENTO, E.P. do. et al. Prospecção no universo das águas: a ...

dos atores sinalizados nas 36 reuniões das CER, revistos e reagrupados na primeira oficina nacional de construção de cenários, ${ }^{21}$ em número de 23.

Resulta do teste de plausibilidade a identificação de cenários com maior ou menor apoio dos atores e, portanto, maior ou menor plausibilidade, caso os atores mantenham suas posições ao longo do período de cenarização. Orienta, desta forma, a definição de quais cenários serão retidos para o trabalho de planejamento, na medida em que não é conveniente reter-se apenas dois cenários ${ }^{22}$ ou mais do que cinco. Na escolha devem prevalecer alguns critérios tais como: a) selecionar os cenários extremos, ou seja, aquele com maior apoio e outro, com menor apoio, já que uma das funções dos cenários é abarcar o maior espaço de futuros plausíveis $^{23}$; b) guardar os cenários com maior distinção entre eles, pois cenários muito similares não servem, pois apenas acumulam dúvidas no processo de monitoramento.

No caso do PNRH foram retidos três cenários dentre os seis inicialmente desenhados pela investigação morfológica, conforme podem ser constatados nos quadros a seguir:

${ }^{21}$ Os participantes da oficina foram representantes de ministérios, agências governamentais, governos estaduais, sociedade civil, além de especialistas em assuntos de relevância para os cenários.

${ }^{22}$ A retenção de dois cenários sempre provoca a dicotomia tola entre ruim/pessimista e bom/otimista, como se esse posicionamento não dependesse do olhar de cada ator. A situação de mais do que cinco cenários, por sua vez, torna muito difícil às organizações ou atores trabalharem o monitoramento do seu contexto externo.

${ }^{23}$ Mas também pelo fato de que cenários pouco prováveis são importantes, na medida em que se observa socialmente a possibilidade daquilo que Boudon (1999), entre outros, denominou de "efeito perverso": todos os atores agem racionalmente, mas o resultado é irracional para cada um deles. 
NASCIMENTO, E.P. do. et al. Prospecção no universo das águas: a ...

Quadro 2: Cenários de recursos hídricos selecionados, Brasil 2020

Cenário 1: Água para todos

Sob influência de um mundo que cresce de maneira integrada e contínua, o Brasil adota, gradativamente, um modelo de desenvolvimento que caminha no sentido da redução da pobreza e das desigualdades sociais, graças ao forte índice de crescimento econômico e de políticas sociais consistentes e integradas. Dessa forma, as atividades econômicas se expandem em todo o País, incluindo a agricultura irrigada, a instalação de usinas hidrelétricas, a expansão do biocombustivel e da energia eólica, além de hidrovias e da infra-estrutura urbana, com fortes, porém declinantes, impactos sobre os recursos hídricos. Graças a uma gestão operativa e significativos investimentos na proteção dos recursos hídricos, bem como a adoção de novas tecnologias, observa-se uma redução dos danos sobre a qualidade e disponibilidade das águas. Impulsionado em parte pelos freqüentes conflitos, o País, aos poucos, encontra uma forma mais eficaz no uso das águas e na contemplação de seu uso múltiplo.

\section{Cenário 2: Água para alguns}

Tanto o mundo como o Brasil são regidos por forte dinamismo excludente, com grande crescimento das atividades econômicas no País, fortes impactos sobre os recursos hídricos e aumento dos bolsões de pobreza e dos índices de desigualdade. A crescente demanda de energia conduz a instalação de usinas hidrelétricas, biocombustivel, hidrovias e infra-estrutura em geral. Apesar da demanda, a redde de saneamento cresce medianamente por razão dos pequenos e seletivos investimentos. A degradação dos recursos hídricos é notória, como resultante dessas atividades e da gestão liberal que se implanta, com planos inoperantes, participação social formal e pouca regulamentação e fiscalização no uso das águas. Assim, os conflitos e os problemas dos recursos hidricos crescem, e a degradação ambiental compromete a sua qualidade e quantidade. $O$ uso múltiplo das águas é mal resolvido por causa das pressões econômicas, particularmente da área de exportação. 
NASCIMENTO, E.P. do. et al. Prospecção no universo das águas: a ...

\section{Cenário 3: Água para poucos}

O Brasil não consegue aproveitar as poucas oportunidades de um mundo instável e fragmentado, e tem um pequeno crescimento das atividades econômicas e das infra-estruturas urbana e de logística. O resultado do pequeno crescimento econômico também não expande significativamente o fornecimento de energia por falta de investimentos. Estes, em relação à proteção de recursos hídricos são também exíguos, seletivos e corretivos, sob uma gestão estatal pouco eficiente. Assim, os conflitos e problemas, em torno da oferta e qualidade dos recursos hídricos, crescem, particularmente nas regiões hidrológicas já deficientes e localidades já problemáticas. A contaminação das águas subterrâneas, em algumas regiões hidrográficas, por sua vez, agrava-se.

Fonte: PNRH, 2006b

5. Desenvolvimento dos cenários selecionados

Aqueles arquétipos de cenários selecionados são objeto de desenvolvimento, ou seja, descrição pormenorizada, segundo uma matriz previamente construída na qual as principais variáveis e dimensões do escopo do objeto são contemplados. Em alguns casos adota-se o sistema de descrição das etapas da trajetória do cenário, com segmentação do período selecionado. Não foi o caso do PNRH, no qual seus cenários foram descritos de forma sucinta, primeiramente em sua filosofia.

6. Comparação e quantificação dos cenários finais

O sexto passo da metodologia adotada consistiu na comparação e quantificação simplificada dos cenários finais que o quadro a seguir apresenta de maneira sintética: 
NASCIMENTO, E.P. do. et al. Prospecção no universo das águas: a ...

Quadro 3: Comparação dos cenários de Recursos Hídricos
selecionados, Brasil 2020

\begin{tabular}{|l|c|c|c|}
\hline \multicolumn{1}{|c|}{ Indicadores / Cenários } & Água para Todos & Água para Alguns & Água para Poucos \\
\hline População do Brasil em milhões & 209 & 219 & 228 \\
\hline PIB em trilhões (reais) & 3.631 & 3.125 & 2.315 \\
\hline Taxa de crescimento (\%.a) & $4,5 \%$ & $3.5 \%$ & $1,5 \%$ \\
\hline PIB per capita (US\$) & $\begin{array}{c}\text { Longo ciclo de } \\
\text { prosperidade }\end{array}$ & $\begin{array}{c}\text { Dinamismo } \\
\text { excludente }\end{array}$ & $\begin{array}{c}\text { Instabilidade e } \\
\text { fragmentação }\end{array}$ \\
\hline Cenários mundiais & $\begin{array}{c}\text { Desenvolvimento } \\
\text { integrado }\end{array}$ & $\begin{array}{c}\text { Modernização } \\
\text { com exclusão }\end{array}$ & $\begin{array}{c}\text { Estagnação e } \\
\text { pobreza }\end{array}$ \\
\hline Cenários nacionais & $\begin{array}{c}\text { Grande crescimento, } \\
\text { médios impactos } \\
\text { Atividades produtivas: indústria, } \\
\text { agricultura e pecuária }\end{array}$ & $\begin{array}{c}\text { Grande } \\
\text { crescimento, fortes } \\
\text { impactos }\end{array}$ & $\begin{array}{c}\text { Pequeno crescimento } \\
\text { com médios } \\
\text { impactos }\end{array}$ \\
\hline Geração de energia hidrelétrica & Forte expansão & Forte expansão & Pequena expansão \\
\hline Saneamento & $\begin{array}{c}\text { Estatal, com } \\
\text { eficiência, propenso } \\
\text { à universalização }\end{array}$ & $\begin{array}{c}\text { Participação } \\
\text { privada, com } \\
\text { pouca expansão }\end{array}$ & $\begin{array}{c}\text { Estatal sem } \\
\text { eficiência }\end{array}$ \\
\hline $\begin{array}{l}\text { Gestão de recursos hídricos } \\
\text { (SINGREH) }\end{array}$ & $\begin{array}{c}\text { Operativa } \\
\text { (predomínio da visão } \\
\text { de gestão integrada) }\end{array}$ & $\begin{array}{c}\text { Economicista } \\
\text { (predomínio da } \\
\text { visão econômica) }\end{array}$ & $\begin{array}{c}\text { Burocrática } \\
\text { (predomínio da } \\
\text { visão cartorial) }\end{array}$ \\
\hline $\begin{array}{l}\text { Investimentos e despesas públicas } \\
\text { em proteção e gestão de RH }\end{array}$ & $\begin{array}{c}\text { Grandes, massivos } \\
\text { e corretivos }\end{array}$ & $\begin{array}{c}\text { Médios, seletivos } \\
\text { e corretivos }\end{array}$ & $\begin{array}{c}\text { Pequenos, seletivos } \\
\text { e corretivos }\end{array}$ \\
\hline
\end{tabular}

Fonte: PNRH, 2006b

7. Identificação da base de sustentação da estratégia do plano

Elaborados os cenários, inicia-se a definição da base sobre a qual o plano, ou seja, o conjunto de programas e projetos vai repousar.

Há três procedimentos habitualmente utilizados nesse caso: a) escolhe-se o cenário julgado mais interessante do ponto de vista dos construtores ou o mais provável; b) constrói-se uma visão de futuro, ou então, c) define-se o campo de uma estratégia robusta, por meio da identificação de recorrências nos diversos cenários.

Cada um dos procedimentos adotados tem, evidentemente, vantagens e desvantagens, e a escolha se faz tomando-se em consideração alguns critérios básicos.

Opta-se pela primeira alternativa - cenário mais plausível quando entre os cenários algum se destaca por sua plausibilidade e 
NASCIMENTO, E.P. do. et al. Prospecção no universo das águas: a ...

convergência de interesse por parte dos construtores. No caso do PNRH havia muita convergência em relação ao primeiro cenário, mas muita descrença de que este viesse a ocorrer.

A opção pela segunda alternativa - visão de futuro - se dá quando há uma boa convergência de interesse e de ideologia entre os construtores. Não era o caso do PNRH, pois que os atores relevantes possuíam visões de mundo e sociedade muito distintas, e mesmo fortemente contraditórias. É muito difícil se reunir, em uma mesma visão, ambientalistas e "barragistas", movimentos populares e agronegócio, apenas para citar dois exemplos dos mais evidentes.

Finalmente, adota-se a opção se construir uma estratégia robusta no caso da confluência de duas situações: as alternativas anteriores serem pouco recomendáveis e os diversos cenários apresentarem elementos comuns.

Os cenários selecionados para o PNRH tinham em seu conjunto, ou na maior parte deles, a característica comum de terem elementos compartilhados, e dificuldades na adoção de uma das alternativas anteriores. Dessa forma, adotou-se esta última alternativa.

\section{A estratégia robusta para a elaboração do PNRH}

O Plano Nacional de Recursos Hídricos gerou três cenários nos quais se podem identificar oportunidades e ameaças comuns.

A principal ameaça ao futuro das águas no Brasil decorre da possibilidade de uma elevada expansão das atividades econômicas e do volume de consumo no meio urbano, não acompanhadas pelo olhar proativo das políticas públicas, de novas tecnologias redutoras de uso dos recursos hídricos, e pela ausência de mudanças no padrão de consumo.

Um exemplo é a possibilidade real de crescimento da exportação de produtos oriundos da agricultura de irrigação e da pecuária intensiva, sem o acompanhamento da correspondente orientação para adoção de tecnologias e práticas ambientalmente corretas. 
NASCIMENTO, E.P. do. et al. Prospecção no universo das águas: a ...

Uma segunda se relaciona menos com o ritmo crescente da demanda de água, e mais com a capacidade de sua boa gestão, tendo em vista que o Estado não tem tradição e os interesses particulares tendem a se sobrepor, particularmente aqueles provindos dos setores mais bem aquinhoados economicamente. A gestão dos recursos hídricos aparece pelo menos em dois cenários como complicada e ineficiente.

Uma terceira ameaça decorre dos reduzidos investimentos no saneamento, presentes em dois cenários igualmente, com repercussões negativas sobre qualidade e disponibilidade das águas.

Finalmente, são ameaça especial os conflitos que tendem a se agravar no País, particularmente nas regiões onde se espera que ocorra um grande crescimento da demanda de água. No caso específico, o grande Brasil Central, que vai do Mato Grosso do Sul ao Piauí, passando pelo interior de São Paulo, e em zonas específicas, conhecidas por sua escassez de recursos hídricos, como o Nordeste e o Rio Grande do Sul, entre outros.

Acompanhando esse raciocínio, o PNRH destacou como principal oportunidade a elevação da consciência ambiental e a expansão entre os diversos atores da consciência sobre a importância e valorização dos recursos hídricos, tanto para garantir o desenvolvimento econômico, quanto para assegurar o bem-estar social e a sustentabilidade ambiental.

Essa oportunidade, por sua vez, está relacionada ao fato de que o mundo necessita de um volume cada vez maior de recursos hídricos, e estes sofrem de uma restrição crescente, tanto no acesso quanto na qualidade, enquanto o Brasil é um dos países mais bem aquinhoados com recursos hídricos. Esse aumento de demanda é acompanhado por uma consciência ambiental crescente no âmbito da população brasileira, reconhecidamente detentora de costumes deletérios em relação ao uso da água.

Assim, a estratégia robusta considerada nos cenários do plano apresenta seis aspectos que requerem o foco de atenção, e constituem a base da elaboração dos programas: 
NASCIMENTO, E.P. do. et al. Prospecção no universo das águas: a ...

1. Consolidação do marco legal que possibilite superar as ambigüidades existentes na legislação associada às águas de domínio da União e dos Estados, em especial das águas subterrâneas, e sua interface com os planos diretores municipais para reduzir o impacto do processo de ocupação e uso do solo.

2. Fortalecimento do sistema institucional de gestão: considerado, a partir da Constituição Federal, como base de integração dos diversos agentes e usuários de água, e que repercute na eficaz geração e aplicação das políticas, nacional e estaduais, de recursos hídricos; o sistema de gestão necessita de adequada atenção na aplicação dos princípios, fundamentos, diretrizes e instrumentos das diversas políticas (nacional, estaduais, municipais e distrital), associadas à educação e capacitação em educação ambiental no uso e conservação da água.

3. Ampliação e enriquecimento dos canais de participação social visando a uma democratização efetiva no processo de planejamento e no acesso aos recursos hídricos, assim como a harmonia (uso múltiplo, integrado e conjuntivo) dos interesses distintos dos demandantes por recursos hídricos, respeitando as vazões que assegurem a sustentabilidade ambiental-ecológica; fóruns que podem assegurar uma superação da visão setorial de cada usuário, criando condições de interação, gerando planos institucionais integrados entre diversos agentes, em variados âmbitos nos territórios, de acordo com as suas potencialidades e vocações.

4. Proposição de formas de integração de políticas públicas: a partir dos aspectos anteriores, observa-se a importância dessa integração para a geração de um futuro sem agravamento da situação dos recursos hídricos brasileiros.

5. Contribuição para acelerar o processo de desconcentração econômica e equidade social atualmente em curso no País.

6. Disseminação de atitude proativa nas regiões estratégicas e críticas, para evitar o agravamento de problemas hídricos e de conflitos relacionados. 
NASCIMENTO, E.P. do. et al. Prospecção no universo das águas: a ...

7. Fortalecimento das ações e políticas de educação, capacitação, mobilização social, informação e comunicação perante toda a população.

\section{Conclusões}

O que proporcionou a metodologia prospectiva adotada pelo PNRH? Aparentemente, conforme descrito anteriormente:

- Permitiu o envolvimento de uma quantidade considerável de atores, difícil em um país de dimensões continentais como o Brasil, dando aos cenários, e ao plano, uma legitimidade que de outra forma não teria;

- Assegurou o relacionamento, de forma sistêmica, entre variáveis e atores, enriquecendo a compreensão do sistema de recursos hídricos do País, e os principais riscos que envolvem sua evolução;

- Possibilitou o enunciado de futuros distintos e coerentes, entre atores tão divergentes, em comunhão com o conhecimento dos especialistas;

- Identificou um conjunto de oportunidades e ameaças comuns aos diversos cenários, atribuindo um caráter novo ao plano;

- Criou uma base para a elaboração dos programas e projetos, possibilitando uma ação antecipatória às políticas públicas, e um instrumento de monitoramento a ser desenvolvido;

- Enfim, se constituiu em uma referência para a elaboração de futuros planos estaduais e de bacia.

Resta saber se, de fato, criou as condições favoráveis para a construção de um pacto político e social em torno da gestão dos recursos hídricos no Brasil. O que só se poderá vislumbrar em uma análise futura.

No entanto, a construção de cenários, em parte pelo exíguo tempo, não chegou às suas últimas conseqüências como instrumento de gestão. De um lado, não se completou do ponto de vista da 
NASCIMENTO, E.P. do. et al. Prospecção no universo das águas: a ...

quantificação das variáveis nos diversos cenários selecionados. De outro lado, não se desdobrou em uma focalização em cada uma das 12 regiões hidrográficas em que o País foi dividido. Dessa forma, a possibilidade de monitoramento da aplicação do plano e desdobramento dos cenários ficou prejudicada.

Os desafios que restaram, portanto, diz respeito à focalização regional dos cenários nas regiões hidrográficas brasileiras, à quantificação de cada um dos cenários, e, finalmente, à divulgação do Plano. Esta é fundamental para que haja uma apropriação efetiva por parte dos agentes estatais e dos atores econômicos e sociais das oportunidades e ameaças que nos cercam no futuro próximo em relação à gestão dos recursos hídricos. Afinal, quanto mais rápido adotarmos medidas antecipatórias nas regiões em que os recursos hídricos tendem a se tornar críticos menos problemas e sofrimentos teremos.

\section{Referências bibliográficas}

AGÊNCIA NACIONAL DE ÁGUAS. O estado das águas no Brasil. Brasília, 1999.

AGÊNCIA NACIONAL DE ÁGUAS. Superintendência de Planejamento de Recursos Hídricos. Disponibilidade de recursos hídricos por regiões hidrográficas. Brasília, 2002a.

AGÊNCIA NACIONAL DE ÁGUAS. Superintendência de Planejamento de Recursos Hídricos. Indicadores de saneamento por regiões hidrográficas. Brasília, $2002 \mathrm{~b}$.

AGÊNCIA NACIONAL DE ÁGUAS. Superintendência de Planejamento de Recursos Hídricos. Demandas de recursos hídricos por regiões hidrográficas. Brasília, 2002c. 
NASCIMENTO, E.P. do. et al. Prospecção no universo das águas: a ...

AGÊNCIA NACIONAL DE ÁGUAS. Superintendência de Planejamento de Recursos Hídricos. Disponibilidade de recursos hídricos por regiões hidrográficas. Brasília, 2002d.

AGÊNCIA NACIONAL DE ÁGUAS. Superintendência de Informações Hidrológicas. Empreendimentos hidroelétricos em operação, em construção e outourgados nas regiões hidrográficas brasileiras. Brasília, 2002e. Disponível em: $<$ http://www.aneel.gov.br $>$.

AGÊNCIA NACIONAL DE ÁGUAS. Atlas de energia elétrica do Brasil. Brasília, 2002f.

BOUDON, Raymond. Effets pervers et ordre social. Paris: PUF, 1989.

CHRISTOFIDIS, D. Irrigação, a fronteira hídrica na produção de alimentos. In: Irrigação e tecnologia. ITEM, 2002. Brasília, 2002b. p. 46-55.

COIMBRA, R. M.; ROCHA, L. C.; BEEKMAN, G. B. Recursos hídricos: conceitos, desafios e capacitação. Brasília: ANEEL, 1999.

EMPRESA BRASILEIRA DE PESQUISA AGROPECUÁRIA. Vulnerabilidade das terras brasileiras à degradação. Rio de Janeiro, 2002.

EDEN, C. Strategic management as a social process. Journal of Management Studies, vol. 29, 799-811.

GODET, Michel. Manual de Prospectiva Estratégica: da antecipação à ação. Lisboa: Publicações Don Quixote, 1993. 
NASCIMENTO, E.P. do. et al. Prospecção no universo das águas: a ...

. Le choc de 2006. Démographie, croissance, emploi. Paris: Odile Jacob, 2003.

HEIJDEN, Klees Van Der. Planejamento de cenários: a arte da conversação estratégica. Porto Alegre: Bookman, 2004.

KAHN, H. e WIENER, A. The year 2000. Macmillan: New York, 1967.

MARQUES, E. Método Prospex de Elaboração de Cenários: Manual de Aplicação. Brasília, DF: Ministério do Meio Ambiente. Secretaria de Recursos Hídricos, 2004.

MINISTÉRIO DO MEIO AMBIENTE. Secretaria de Recursos Hídricos. Ministério do Meio Ambiente. Recursos hídricos no Brasil. Brasília, 1998a.

MINISTÉRIO DO MEIO AMBIENTE, Secretaria de Recursos Hídricos. Plano Nacional de Recursos Hídricos. FGV, Brasília, 1998b. $10 \mathrm{v}$.

MINISTÉRIO DO MEIO AMBIENTE. Secretaria de Recursos Hídricos. Recursos hídricos: conjunto de normas legais. Brasília, MMA, 2004, 3. ed.

MINISTÉRIO DO MEIO AMBIENTE. Secretaria de recursos hídricos. Documento Base de Referência - DBR. Brasília, 2005. $292 \mathrm{p}$.

MINISTÉRIO DO MEIO AMBIENTE. Caderno da Região Hidrográfica do Uruguai. Secretaria de Recursos Hídricos. Brasília: MMA, 2006a. 128 p. 
NASCIMENTO, E.P. do. et al. Prospecção no universo das águas: a ...

MINISTÉRIO DO MEIO AMBIENTE. Caderno da Região Hidrográfica Atlântico Leste. Secretaria de Recursos Hídricos Brasília: MMA, 2006b. 156 p.

MINISTÉRIO DO MEIO AMBIENTE. Caderno da Região Hidrográfica do Paraná. Secretaria de Recursos Hídricos Brasília: MMA, 2006c. 240 p.

MINISTÉRIO DO MEIO AMBIENTE. Caderno da Região Hidrográfica Amazônica. Secretaria de Recursos Hídricos Brasília: MMA, 2006d. 124 p.

MINISTÉRIO DO MEIO AMBIENTE. Caderno da Região Hidrográfica Atlântico Sudeste. Secretaria de Recursos Hídricos - Brasília: MMA, 2006e. 140 p.

MINISTÉRIO DO MEIO AMBIENTE. Caderno da Região Hidrográfica Atlântico Nordeste Oriental. Secretaria de Recursos Hídricos - Brasília: MMA, 2006f. 104 p.

MINISTÉRIO DO MEIO AMBIENTE. Caderno da Região Hidrográfica Atlântico Nordeste Ocidental. Secretaria de Recursos Hídricos - Brasília: MMA, 2006g. 128 p.

MINISTÉRIO DO MEIO AMBIENTE. Caderno da Região Hidrográfica Atlântico Sul. Secretaria de Recursos Hídricos Brasília: MMA, 2006h. 128 p.

MINISTÉRIO DO MEIO AMBIENTE. Caderno da Região Hidrográfica São Francisco. Secretaria de Recursos Hídricos Brasília: MMA, 2006i. 148 p.

MINISTÉRIO DO MEIO AMBIENTE. Caderno da Região Hidrográfica do Paraguai. Secretaria de Recursos Hídricos Brasília: MMA, 2006j. 128 p. 
NASCIMENTO, E.P. do. et al. Prospecção no universo das águas: a ...

MINISTÉRIO DO MEIO AMBIENTE. Caderno da Região Hidrográfica do Tocantins-Araguaia. Secretaria de Recursos Hídricos - Brasília: MMA, 2006k. 131 p.

MINISTÉRIO DO MEIO AMBIENTE. Caderno da Região Hidrográfica do Parnaíba. Secretaria de Recursos Hídricos Brasília: MMA, 20061. 184 p.

MINISTÉRIO DO MEIO AMBIENTE. Caderno setorial de recursos hídricos: saneamento. Secretaria de Recursos Hídricos Brasília: MMA, 2006m. 68 p.

MINISTÉRIO DO MEIO AMBIENTE. Caderno setorial de recursos hídricos: agropecuária. Secretaria de Recursos Hídricos Brasília: MMA, 2006n. 96 p.

MINISTÉRIO DO MEIO AMBIENTE. Caderno setorial de recursos hídricos: transporte hidroviário. Secretaria de Recursos Hídricos - Brasília: MMA, 2006o. 120 p.

MINISTÉRIO DO MEIO AMBIENTE. Caderno setorial de recursos hídricos: geração de energia hidrelétrica. Secretaria de Recursos Hídricos - Brasília: MMA, 2006p. 112 p.

MINISTÉRIO DO MEIO AMBIENTE. Caderno setorial de recursos hídricos: indústria e turismo. Secretaria de Recursos Hídricos - Brasília: MMA, 2006q. 80 p.

MINTZBERG, H. The design school, reconsidering the basics premises of strategic management. Strategic Management Journal, v. 11, 1990, 171-195.

PORTO, Claudio; BUARQUE, Sergio; NASCIMENTO, Elimar. Cinco cenários para o Brasil, 2001-2003. Rio de Janeiro: Nórdica, 2001. 
NASCIMENTO, E.P. do. et al. Prospecção no universo das águas: a ...

PLANO NACIONAL DE RECURSOS HÍDRICOS. Panorama e estado dos recursos hídricos no Brasil. Volume 1. Ministério do Meio Ambiente, Secretaria de Recursos Hídricos. Brasília: MMA, 2006 a.

PLANO NACIONAL DE RECURSOS HÍDRICOS. Águas para o futuro - cenários para 2020. Volume 2. Ministério do Meio Ambiente, Secretaria de Recursos Hídricos. Brasília: MMA, $2006 \mathrm{~b}$.

PLANO NACIONAL DE RECURSOS HÍDRICOS. Diretrizes. Volume 3. Ministério do Meio Ambiente, Secretaria de Recursos Hídricos. Brasília: MMA, 2006c.

PLANO NACIONAL DE RECURSOS HÍDRICOS. Programas nacionais e metas. Volume 4. Ministério do Meio Ambiente, Secretaria de Recursos Hídricos. Brasília: MMA, 2006d.

PNUMA - Programa das Nações Unidas para Meio Ambiente. Perspectivas do Meio Ambiente Mundial 2002 - Geo.-3 Passado, Presente e Futuro. Publicado em parceria com o Instituto Brasileiro do Meio Ambiente e dos Recursos Naturais Renováveis - IBAMA e Universidade Livre da Mata Atlântica UMA. Brasília, 2004.

REBOUÇAS, A.C.; BRAVA, B; TUNDISI, J.G. (Org.) Águas doces do Brasil: capital ecológico, uso e conservação. São Paulo: Escrituras, 1999.

SCWARTZ, Peter. A arte da previsão. Planejando o futuro em um mundo de incertezas. São Paulo: Página Aberta, 1995.

TUCCI, C.E. Apreciação do Plano Nacional de Recursos Hídricos e visão prospectiva dos programas e ações. Documento de apoio às ações de planejamento da Agência Nacional de Águas. Brasília, 2001. 53 p. 
NASCIMENTO, E.P. do. et al. Prospecção no universo das águas: a ...

TUCCI, C.E.M.; ESPAÑOL, I.; CORDEIRO NETTO, O. M. C.

Gestão da água no Brasil. Brasília: Unesco, 2001.

VÂNIA DA SILVA NUNES Agricultura irrigada $\mathbf{X}$ saúde ambiental: existe um conflito

http://www21.sede.embrapa.br/noticias/artigos/2001/artigo.2004. Acessado em 10 set. 2005.

VIEIRA, A. P. Planejamento hidroviário: esboço tentativo de planejamento. Brasília, 2002.

VIEIRA. S. Turismo. Turismo no Brasil. Disponível em: $<$ http://geocities.yahoo.com.br/suelen_hotelaria/mat_turismo_no_b rasil_novos_rumos.html >. Acesso em out. 2002.

WACK, p. Scenarios, uncharted waters ahead. Harvard Business Review set.-out. 1985, 73-90.

WWF - Observatório das águas: a água e o poder público no Brasil. Brasilia, Programa água para a vida, 2004 (apresentação Denise Hamú e Samuel Barreto)

WORLD WATER COUNCIL. World water vision. Earthscan Publications Ltd, Londres, 2000 
NASCIMENTO, E.P. do. et al. Prospecção no universo das águas: a ...

\section{ANEXO 1}

\section{PROSPECÇÃO NO UNIVERSO DAS ÁGUAS: A EXPERIÊNCIA DA CONSTRUÇÃO DE CENÁRIOS NO PLANO NACIONAL DE RECURSOS HÍDRICOS NO BRASIL, 2005-2006}

\section{LISTA DE VARIÁVEIS RELEVANTES (CENARIZAÇÃO PROSPECTIVA - PNRH)}

Variáveis relevantes, do ponto de vista da cenarização prospectiva, são aquelas que se relacionam com o sistema em análise, ou seja, os corpos de águas nas regiões hidrográficas brasileiras. Para efeito do PNRH foram definidas 53 variáveis, apresentadas abaixo.

\begin{tabular}{|c|c|c|}
\hline & Variável & Descrição \\
\hline 1. & Qualidade da água & $\begin{array}{l}\text { Condição físico-química-biológica dos corpos d'água, superficiais } \\
\text { e subterrâneos, em um determinado momento, em relação aos } \\
\text { usos preponderantes, atuais e futuros. }\end{array}$ \\
\hline 8. & $\begin{array}{l}\text { Quantidade de água } \\
\text { superficial disponível }\end{array}$ & \begin{tabular}{|l}
$\begin{array}{l}\text { Regime de disponibilidade quantitativa (natural) de água } \\
\text { superficial. }\end{array}$ \\
\end{tabular} \\
\hline 9. & $\begin{array}{l}\text { Quantidade de água } \\
\text { subterrânea disponível }\end{array}$ & \begin{tabular}{|l} 
Disponibilidade quantitativa (natural) de água \\
explotável e aquela com potencial de explotação.
\end{tabular} \\
\hline 10. & $\begin{array}{l}\text { Alteração do regime } \\
\text { natural dos corpos de } \\
\text { água }\end{array}$ & $\begin{array}{l}\text { Alterações nos corpos d'água decorrentes de atividades humanas; } \\
\text { consideram-se as alterações morfológicas e hidrológicas, ou seja, } \\
\text { na forma e vazão, geradas por: impermeabilização do solo, } \\
\text { canalização, retificação, dragagem, barramentos, diques, } \\
\text { processos erosivos, assoreamento, transposições, entre outros. }\end{array}$ \\
\hline 11. & $\begin{array}{l}\text { Eventos Hidrológicos } \\
\text { Críticos }\end{array}$ & $\begin{array}{l}\text { Ocorrência de situações provenientes de fenômenos de excesso ou } \\
\text { escassez hídrica, respectivamente, enchentes e secas; também se } \\
\text { consideram a freqüência e intensidade dessas ocorrências. }\end{array}$ \\
\hline 12. & Clima & $\begin{array}{l}\text { Regime climático, considerando a interação entre os elementos do } \\
\text { clima (precipitação, temperatura, temperatura na superfície do } \\
\text { mar, evaporação, dentre outros); o regime de chuvas, } \\
\text { considerando sua freqüência, intensidade e duração; além da } \\
\text { variabilidade climática e potenciais mudanças. }\end{array}$ \\
\hline 13. & $\begin{array}{l}\text { Água para manutenção } \\
\text { de ecossistemas }\end{array}$ & $\begin{array}{l}\text { Disponibilidade de água em quantidade, qualidade e em regime } \\
\text { fluvial suficientes para a manutenção da biota associada. }\end{array}$ \\
\hline 14. & Bioinvasão & $\begin{array}{l}\text { Introdução intencional ou acidental de organismos (macro ou } \\
\text { microscópicos) em ambientes onde não estavam presentes. }\end{array}$ \\
\hline 15 . & $\begin{array}{l}\text { Conservação dos } \\
\text { biomas }\end{array}$ & $\begin{array}{l}\text { Estado de conservação dos biomas, considerando a variação dos } \\
\text { diferentes tipos de cobertura vegetal ao longo do tempo e } \\
\text { respectiva superfície ocupada, a dimensão e distribuição dos } \\
\text { espaços territoriais sob a forma de áreas protegidas. Considera-se } \\
\text { ainda, a ocorrência de fauna e práticas de uso dos recursos } \\
\text { naturais associadas aos diferentes biomas. }\end{array}$ \\
\hline
\end{tabular}


NASCIMENTO, E.P. do. et al. Prospecção no universo das águas: a ...

\begin{tabular}{|c|c|c|}
\hline & Variável & Descrição \\
\hline 16. & $\begin{array}{l}\text { Dinâmica de uso e } \\
\text { ocupação do solo }\end{array}$ & $\begin{array}{l}\text { Dinâmica de uso e ocupação do solo, compreendendo a área de } \\
\text { urbanização, pecuária, agricultura irrigada e de sequeiro, } \\
\text { preservação e terras a serem recuperadas, com suas dimensões, } \\
\text { distribuições e aptidões, abrangendo as unidades territoriais } \\
\text { utilizadas para a formulação de políticas (bacias hidrográficas e } \\
\text { unidades de planejamento e gestão de recursos hídricos). }\end{array}$ \\
\hline 17. & Sistemas estuarinos & $\begin{array}{l}\text { Estado de conservação dos sistemas estuarinos, considerando a } \\
\text { repercussão da gestão dos recursos hídricos, do uso e ocupação do } \\
\text { solo e de atividades antrópicas sobre esses sistemas. }\end{array}$ \\
\hline 18. & $\begin{array}{l}\text { Mortalidade/ morbidade } \\
\text { por doenças de } \\
\text { veiculação hídrica }\end{array}$ & $\begin{array}{l}\text { Ocorrência de mortalidade e morbidade humanas, provocada por } \\
\text { doenças de veiculação hídrica. }\end{array}$ \\
\hline 19. & $\begin{array}{l}\text { Desenvolvimento } \\
\text { humano }\end{array}$ & $\begin{array}{l}\text { Nível de desenvolvimento humano,sob a ótica da desigualdade social, } \\
\text { considerando a renda, longevidade, educação e padrão de consumo. }\end{array}$ \\
\hline 20. & $\begin{array}{l}\text { Infra-estrutura de } \\
\text { controle da poluição } \\
\text { doméstica }\end{array}$ & $\begin{array}{l}\text { Níveis de atendimento da população pelos serviços de saneamento } \\
\text { ambiental, considerando infra-estrutura de coleta, tratamento e } \\
\text { disposição final de esgoto sanitário; coleta, tratamento e } \\
\text { disposição adequada dos resíduos sólidos. }\end{array}$ \\
\hline 21. & $\begin{array}{l}\text { Abastecimento } \\
\text { humano }\end{array}$ & $\begin{array}{l}\text { Graus de acesso da população a água potável, considerando a } \\
\text { utilização de soluções alternativas de abastecimento público. }\end{array}$ \\
\hline 22. & $\begin{array}{l}\text { Segurança alimentar e } \\
\text { nutricional }\end{array}$ & Características alimentar, e nutricional, da água. \\
\hline 23. & Desigualdade social & $\begin{array}{l}\text { Diferença, para mais e para menos, entre os níveis sócio- } \\
\text { econômicos da população. }\end{array}$ \\
\hline 24. & Diversidade social & $\begin{array}{l}\text { Reconhecimento da diversidade social e o respeito às } \\
\text { particularidades dos grupos sociais, tradicionais e movimentos } \\
\text { sociais, e suas conseqüências na gestão de recursos hídricos. }\end{array}$ \\
\hline 25. & $\begin{array}{l}\text { Organização da } \\
\text { sociedade civil }\end{array}$ & $\begin{array}{l}\text { Organização da sociedade, considerando o grau de associativismo } \\
\text { e outras formas de organização não setorial dedicados à discussão } \\
\text { dos temas relacionados aos recursos hídricos e ao Meio Ambiente. }\end{array}$ \\
\hline 26. & \begin{tabular}{|l|} 
Transparência e acesso \\
à informação
\end{tabular} & $\begin{array}{l}\text { Facilidade de acesso público à informação de qualidade de forma } \\
\text { sistemática, respeitando princípios éticos na administração pública } \\
\text { e privada; e pela qualidade das informações gerenciais, que } \\
\text { auxiliam a tomada de decisões. }\end{array}$ \\
\hline 27. & $\begin{array}{l}\text { Implementação do } \\
\text { Sistema de Informação }\end{array}$ & $\begin{array}{l}\text { Grau de implementação do Sistema de Informações sobre } \\
\text { Recursos Hídricos, incluindo as ações de planejamento e gestão } \\
\text { da rede hidrometeorológica. }\end{array}$ \\
\hline 28. & $\begin{array}{l}\text { Consideração das } \\
\text { questões de gênero }\end{array}$ & $\begin{array}{l}\text { Reconhecimento da diferença nas relações de mulheres e homens com o } \\
\text { uso da água e suas consequiências na gestão de recursos hídricos. }\end{array}$ \\
\hline 29. & Dinâmica populacional & $\begin{array}{l}\text { Dinamismo próprio da população, considerando o ritmo de seu } \\
\text { crescimento, a população residente em marcos temporais } \\
\text { distintos, concentrações populacionais, bem como seus } \\
\text { movimentos intra-regionais e inter-regionais. }\end{array}$ \\
\hline 30. & Demanda por água & $\begin{array}{l}\text { Quantidade de água necessária para sustentação dos diferentes } \\
\text { usos consuntivos e não consuntivos. }\end{array}$ \\
\hline
\end{tabular}


NASCIMENTO, E.P. do. et al. Prospecção no universo das águas: a ...

\begin{tabular}{|c|c|c|}
\hline \multicolumn{2}{|c|}{ Variável } & Descrição \\
\hline 31. & $\begin{array}{l}\text { Atividade da } \\
\text { agricultura irrigada }\end{array}$ & $\begin{array}{l}\text { Produção agrícola com irrigação, incluindo a infra-estrutura } \\
\text { necessária. }\end{array}$ \\
\hline 32. & Atividade industrial & $\begin{array}{l}\text { Conjunto das atividades industriais, incluindo a infra-estrutura } \\
\text { necessária. }\end{array}$ \\
\hline 33. & $\begin{array}{l}\text { Atividade de } \\
\text { mineração }\end{array}$ & $\begin{array}{l}\text { Aproveitamento mineral, incluindo a prospecção e pesquisa } \\
\text { minerais, a existência de jazidas, os sistemas de disposição de } \\
\text { estéril e rejeitos com seus efluentes e os barramentos, } \\
\text { considerando, ainda, a infra-estrutura necessária. }\end{array}$ \\
\hline 34. & $\begin{array}{l}\text { Atividade de geração } \\
\text { de energia }\end{array}$ & $\begin{array}{l}\text { Geração de energia elétrica: hidrelétricas e termoelétricas } \\
\text { (convencionais e nucleares), considerando, ainda, a infra-estrutura } \\
\text { necessária. }\end{array}$ \\
\hline 35. & Atividade de pesca & $\begin{array}{l}\text { Produção pesqueira comercial e artesanal, considerando, ainda, a } \\
\text { infra-estrutura necessária. }\end{array}$ \\
\hline 36. & $\begin{array}{l}\text { Atividade de } \\
\text { aqüicultura }\end{array}$ & $\begin{array}{l}\text { Produção de organismos aquáticos cultivados com valor } \\
\text { comercial, considerando, ainda, a infra-estrutura necessária. }\end{array}$ \\
\hline 37. & $\begin{array}{l}\text { Atividade de } \\
\text { navegação }\end{array}$ & $\begin{array}{l}\text { Manutenção, operação e utilização dos cursos d'água para } \\
\text { navegaça. Considera-se ainda, a construção de infra-estrutura } \\
\text { hidroviária, com sua a infra-estrutura necessária. }\end{array}$ \\
\hline 38. & $\begin{array}{l}\text { Atividade de turismo e } \\
\text { lazer }\end{array}$ & $\begin{array}{l}\text { Condições qualitativas e quantitativas dos recursos hídricos } \\
\text { necessários ao turismo e lazer. }\end{array}$ \\
\hline 39. & $\begin{array}{l}\text { Atividade agropecuária } \\
\text { e avícola }\end{array}$ & $\begin{array}{l}\text { Produção agrícola de sequeiro, pecuária e avícola, incluindo a } \\
\text { infra-estrutura necessária. }\end{array}$ \\
\hline 40. & $\begin{array}{l}\text { PIB - Produto interno } \\
\text { bruto }\end{array}$ & Alterações no Produto Interno Bruto (PIB). \\
\hline 41. & $\begin{array}{l}\text { Criação de um } \\
\text { mercado internacional } \\
\text { de água bruta }\end{array}$ & $\begin{array}{l}\text { Possibilidade de criação de um mercado internacional para } \\
\text { comercialização de água bruta. }\end{array}$ \\
\hline 42. & $\begin{array}{l}\text { Investimento no setor } \\
\text { de infra-estrutura }\end{array}$ & $\begin{array}{l}\text { Grau de investimentos em infra-estrutura produtiva, considerando } \\
\text { investimentos de capital com possíveis conseqüências em recursos } \\
\text { hídricos. }\end{array}$ \\
\hline 43. & $\begin{array}{l}\text { Eficácia no uso da } \\
\text { água }\end{array}$ & $\begin{array}{l}\text { Grau de eficácia na utilização da água, resultante de pesquisas } \\
\text { tecnológicas, melhoria no manejo dos processos produtivos que } \\
\text { utilizam água (reuso da água, reaproveitamento de resíduos e } \\
\text { efluentes...), treinamento e capacitação no seu uso eficiente. }\end{array}$ \\
\hline 44. & $\begin{array}{l}\text { Gestão das águas } \\
\text { urbanas }\end{array}$ & $\begin{array}{l}\begin{array}{l}\text { Existência de gestão das águas urbanas } \\
\text { implementação. }\end{array} \\
\text { impleu grau de } \\
\end{array}$ \\
\hline 45. & $\begin{array}{l}\text { Enquadramento dos } \\
\text { corpos de água. }\end{array}$ & $\begin{array}{l}\text { Existência de enquadramento dos corpos de água, segundo as } \\
\text { classes de uso definidas na resolução CONANA n }{ }^{\circ} \text { 20/1986. }\end{array}$ \\
\hline 46. & $\begin{array}{l}\text { Existência de planos de } \\
\text { recursos hídricos. }\end{array}$ & $\begin{array}{l}\text { Existência de Planos de Recursos Hídricos, em todos os níveis, } \\
\text { Planos de Bacia Hidrográfica, Planos Estaduais e Plano Nacional } \\
\text { de Recursos Hídricos. }\end{array}$ \\
\hline 47. & $\begin{array}{l}\text { Implementação do proce- } \\
\text { sso de alocação de água e } \\
\text { da outorga de direito de } \\
\text { uso }\end{array}$ & $\begin{array}{l}\text { Grau de implementação do processo de alocação de água e da } \\
\text { outorga de direito de uso. }\end{array}$ \\
\hline
\end{tabular}


NASCIMENTO, E.P. do. et al. Prospecção no universo das águas: a ...

\begin{tabular}{|c|c|c|}
\hline \multicolumn{2}{|r|}{ Variável } & Descricão \\
\hline 48. & $\begin{array}{l}\text { Implementação da } \\
\text { cobrança pelo uso da água }\end{array}$ & $\begin{array}{l}\text { Grau de implementação da cobrança pelo uso dos recursos } \\
\text { hídricos. }\end{array}$ \\
\hline 49. & \begin{tabular}{|l|l} 
Implementação do \\
SISNAMA
\end{tabular} & $\begin{array}{l}\text { Grau de implementação do SISNAMA, considerando o licenciamento } \\
\text { ambiental e o Zoneamento Ecológico Econômico, entre outros. }\end{array}$ \\
\hline 50. & \begin{tabular}{|l|} 
Ações de educação em \\
recursos hídricos e \\
meio ambiente
\end{tabular} & $\begin{array}{l}\text { Ações de educação em recursos hídricos e meio ambiente, } \\
\text { formal e não formal, desenvolvidas nas diversas instâncias da } \\
\text { sociedade. }\end{array}$ \\
\hline 51. & \begin{tabular}{|l|} 
Implementação \\
institucional do \\
SINGREH
\end{tabular} & $\begin{array}{l}\text { Estágio da estruturação, contemplando a efetiva implementação das } \\
\text { instâncias de deliberação, dos órgãos gestores e dos mecanismos } \\
\text { institucionais que criem condições politico-institucionais para a } \\
\text { gestão de recursos hídricos conforme preconizado pela Legislação } \\
\text { Federal. Consideram-se, também, as possibilidades de alteraçôs na } \\
\text { orientação da implementação do SINGREH e os riscos ao modelo } \\
\text { de gestão dos recursos hídricos vigente no País. }\end{array}$ \\
\hline 52. & \begin{tabular}{|l|} 
Implementação de \\
acordos internacionais \\
relativos a RH e MA, \\
ratificados
\end{tabular} & $\begin{array}{l}\text { Reflexo da implementação dos acordos internacionais relativos } \\
\text { a recursos hídricos e meio ambiente. }\end{array}$ \\
\hline 53. & \begin{tabular}{|l|} 
Investimento e despesa \\
pública em proteção e \\
gestão de recursos \\
hídricos
\end{tabular} & $\begin{array}{l}\text { Montante de aplicação de recursos públicos ou privados na } \\
\text { proteção dos recursos hídricos e na capacitação de profissionais } \\
\text { para atuar na gestão de recursos hídricos. }\end{array}$ \\
\hline 54. & $\begin{array}{l}\text { Conflitos internacionais } \\
\text { por água }\end{array}$ & $\begin{array}{l}\text { Existência de conflitos internacionais atuais e potenciais por } \\
\text { recursos hídricos. }\end{array}$ \\
\hline 55. & $\begin{array}{l}\text { Dinâmica do mercado } \\
\text { internacional }\end{array}$ & $\begin{array}{l}\text { Dinâmica de intercâmbio de mercadorias, serviços e } \\
\text { investimentos do Brasil com os demais Países, especialmente a } \\
\text { formação de blocos econômicos e suas repercussões na balança } \\
\text { comercial brasileira. Considera-se a existência de barreiras } \\
\text { ambientais ou sanitárias e as demais formas regulamentação de } \\
\text { colocação de produtos brasileiros no mercado internacional. }\end{array}$ \\
\hline 56. & $\begin{array}{l}\text { Eficiência no serviço } \\
\text { público }\end{array}$ & $\begin{array}{l}\text { Grau de agilidade na implementação das políticas públicas e } \\
\text { dos instrumentos de gestão de recursos hídricos. }\end{array}$ \\
\hline 57. & $\begin{array}{l}\begin{array}{l}\text { Produção do conhecimen- } \\
\text { to para o gerenciamento } \\
\text { dos recursos hídricos }\end{array} \\
\end{array}$ & $\begin{array}{l}\text { Produção de conhecimento para a gestão da oferta, da } \\
\text { demanda, dos conflitos e dos aspectos institucionais. }\end{array}$ \\
\hline 58. & \begin{tabular}{|l|} 
Interação com outros \\
planos e políticas \\
nacionais
\end{tabular} & Grau de integração dos planos e políticas nacionais. \\
\hline 59. & Biotecnologia & $\begin{array}{l}\text { Grau de disseminação do uso de técnica de manipulação dos } \\
\text { organismos vivos (ou parte destes) para produzir ou modificar } \\
\text { produtos, para o melhoramento de plantas e animais, ou para o } \\
\text { desenvolvimento de micro-organismos para uso específico. }\end{array}$ \\
\hline
\end{tabular}

Recebido em outubro de 2008 Aceito em novembro de 2009 